Article

\title{
Polymeric Planar Microcavities Doped with a Europium Complex
}

\author{
Paola Lova ${ }^{1}$, Marco Olivieri ${ }^{1}$, Alba Surace ${ }^{1}$, Gokhan Topcu ${ }^{2}\left(\mathbb{D}\right.$, Mehtap Emirdag-Eanes ${ }^{2}$, \\ Mustafa M. Demir ${ }^{2}$ and Davide Comoretto ${ }^{1, *}$ (1) \\ 1 Dipartimento di Chimica e Chimica Industriale, Università degli Studi di Genova, Via Dodecaneso 31, \\ 16132 Genova, Italy; paola.lova@edu.unige.it (P.L.); olivierimarco11@gmail.com (M.O.); \\ alba.surace@gmail.com (A.S.) \\ 2 Department of Materials Science and Engineering and Department of Chemistry, İzmir Institute of \\ Technology, Urla, 35430 İzmir, Turkey; gokhantopcu@ku.edu.tr (G.T.); mehtapemirdag@iyte.edu.tr (M.E.-E.); \\ mdemir@iyte.edu.tr (M.M.D.) \\ * Correspondence: davide.comoretto@unige.it
}

Received: 12 March 2020; Accepted: 7 April 2020; Published: 10 April 2020

check for updates

\begin{abstract}
Organo-metallic europium complex tetrakis (dibenzoyl methide) triethylammonium $\left(\mathrm{EuD}_{4} \mathrm{TEA}\right)$ shows a sharp emission spectrum, which makes it interesting for photonic applications. In this work, we embedded it into all-polymeric planar microcavities and investigated the effect of the photonic environment on its emission spectrum. To this end, submicron-sized $\mathrm{EuD}_{4} \mathrm{TEA}_{\mathrm{C}}$ crystals were loaded into a blend of polystyrene and carboxylic terminated polystyrene matrix, which served to stabilize the emitter in the polymer and to make the composite processable. The new composite was then casted by spin-coating as a defect layer in a polymeric planar microcavity. Spectroscopic studies demonstrate that fine spectral tuning of the cavity mode on the sharp organometal luminescence is possible and produces spectral redistribution of the fluorophore emission, along with a remarkable cavity quality factor.
\end{abstract}

Keywords: polymer photonic crystals; microcavities; EuD 4 TEA; fluorescence engineering

\section{Introduction}

Organometallic transition metal compounds are particularly attractive for the development of optical devices owing to their large quantum yield and chemical stability [1-3]. Among several of these compounds, europium tetrakis (dibenzoyl methide) triethylammonium $\left(\mathrm{EuD}_{4} \mathrm{TEA}\right)$ shows one of the most efficient emission processes [4-6]. $\mathrm{EuD}_{4} \mathrm{TEA}$ is indeed an organometallic triboluminescent [7] crystal showing an intense and sharp red emission, which is allowed by the europium complexation $[8,9]$. Indeed, its structure consists of four coordinated electron donating groups (1,3-diphenyl-1,3-propanedione), which function as light absorbers; one is triethylamine, which serves to stabilize the complex, and the complexed emissive metal [8,9] (Figure 1). As mentioned above, the material shows an intense and sharp near-band-edge exciton emission at $614 \mathrm{~nm}$, where the triboluminescence also occurs [3,10,11]. In spite of its outstanding emissive properties, $\mathrm{EuD}_{4} \mathrm{TEA}$ applications are currently limited to the sensing of mechanical stimulations using the pristine material, or embedding the material into polymer matrices such as poly methyl methacrylate [10]. These applications are allowed by the triboluminescence process, which is the emission of photons resulting from chemical bond breakage within crystalline particles after the application of a mechanical force [12,13]. On the other hand, the sharp emission of $\mathrm{EuD}_{4}$ TEA together with the crystal robustness makes this compound highly attractive for integration in plastic photonic crystals, a viable approach to produce devices with engineered fluorescence. 


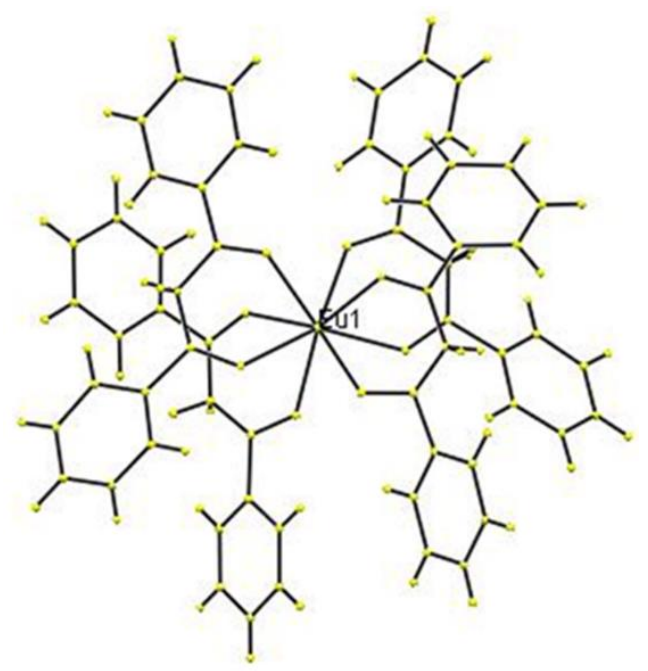

Figure 1. Structure of the europium tetrakis (dibenzoyl methide) triethylammonium $\left(\mathrm{EuD}_{4} \mathrm{TEA}\right)$ complex.

Since their first description in the 1980s [14,15], inorganic photonic crystals have been largely employed to enhance intensity and to obtain directional control of photoluminescence, as well as for lasing, switching, and sensing [16-22]. Only in the last decades, when polymers have entered the spotlight for photovoltaics and emitting devices [23-25], have these materials also become interesting for photonic applications [26-32]. Among polymer photonic structures, monodimensional multilayered photonic crystals, namely distributed Bragg reflectors (DBRs) and planar microcavities, are the simplest from a fabrication and modelling point of view [33]. Moreover, they are already fabricated industrially via melt processing [34,35]. In addition, these systems are highly versatile. Indeed, all-polymer structures have already been demonstrated in coupling with several kinds of emitters including, besides conjugated molecules and polymers [36-38], inorganic nanocrystals [39-42], J-aggregates [43] and perovskites [44,45].

In this work, as a proof of principle, we demonstrate polymer planar microcavities doped with $\mathrm{EuD}_{4} \mathrm{TEA}$ embedded into a blend of polystyrene (PS) and PS carboxi-terminated (PSCT). While the pristine PS serves to increase the viscosity of the starting solution to enhance its processability, PSCT serves to stabilize $\mathrm{EuD}_{4}$ TEA through the $-\mathrm{OH}$ group of the carboxylic PS termination [10]. We study the $\mathrm{EuD}_{4}$ TEA photoluminescence directional and spectral redistribution. Emission lifetime is also discussed to assess radiative enhancement effects.

\section{Materials and Methods}

The synthesis of $\mathrm{EuD}_{4}$ TEA was carried out by the hot injection method [10]. An aliquot (50 mL) of the solution of 1,3-diphenyl-1,3-dipronedione (Sigma-Aldrich; 98\%) in ethanol with a concentration of $58.2 \mathrm{mg} / \mathrm{mL}$ was heated until reflux. Subsequently, the preheated solution of $\mathrm{Eu}\left(\mathrm{NO}_{3}\right)_{3}(52.8 \mathrm{mg} / \mathrm{mL})$ was injected into a vial under vigorous stirring. The $1.42 \mathrm{~g}(14 \mathrm{mmol})$ of triethylamine (Sigma-Aldrich, $\geq 99.5)$ was added to the boiling mixture and the reaction was maintained for $1 \mathrm{~h}$. For the crystallization, the solution was first allowed to slowly cool down to room temperature. Afterwards, it was further crystallized at $4{ }^{\circ} \mathrm{C}$ for $24 \mathrm{~h}$. The crystals were filtrated and washed with cold ethanol, thereafter dried for $24 \mathrm{~h}$ in a vacuum chamber at $40{ }^{\circ} \mathrm{C}$. Figure 1 displays the structure of $\mathrm{EuD}_{4} \mathrm{TEA}$ crystals. The colorless crystals of $\mathrm{EuD}_{4} \mathrm{TEA}$ were composed of an anionic europium complex and a protonated triethylammonium molecule. EuD $\mathrm{D}_{4}$ TEA crystallizes in the monoclinic crystal system with non-centrosymmetric space group $\mathrm{P} 2{ }_{1}$. The structure of $\mathrm{EuD}_{4}$ TEA has europium (III) with eight oxygen atoms coordinated to the 1,3-diphenyl-1,3-propanedianato ligands.

The polymer microcavities were fabricated on glass substrates by alternate spin-coating deposition of a toluene solution ( $35 \mathrm{mg} / \mathrm{mL}$ ) of poly ( $\mathrm{N}$-vinylcarbazole) (PVK; Across Organic; $\mathrm{M}_{\mathrm{W}}=136,600 \mathrm{~g} / \mathrm{mol}$; 
refractive index, $\mathrm{n}=1.68$ ) $[43,46,47]$ and polyacrylic acid (PAA; Sigma-Aldrich; $\mathrm{M}_{\mathrm{W}}=1800 \mathrm{~g} / \mathrm{mol}$; $\mathrm{n}=1.44)$ [43] solubilized in 2-methyl-2-pentanol $(28 \mathrm{mg} / \mathrm{mL})$. The rotation speed was kept at 66 rounds per second. No thermal annealing was performed during the fabrication process. The microcavity layer was placed on 25 bilayers of the two polymers by spin-coating of $\mathrm{EuD}_{4}$ TEA dissolved in a PS $(20 \mathrm{mg} / \mathrm{mL})$ :PSCT $(10 \mathrm{mg} / \mathrm{mL})$ solution in toluene (PS, Sigma Aldrich, MW $=92 \mathrm{~kg} / \mathrm{mol}$; PSCT, Sigma-Aldrich $\mathrm{M}_{\mathrm{W}}=200 \mathrm{~kg} / \mathrm{mol}$ ). The cavity layer was casted at $35 \mathrm{RPS}$. After the deposition of the photoactive material, the microcavity was completed with the deposition of the other 25 bilayers of PAA and PVK. The reference sample was instead fabricated under the same condition casting a layer of $\mathrm{EuD}_{4}$ TEA:PS on a thin film of PAA.

Reflectance, transmittance and emission spectra were collected using setups based on optical fibers connected to a Charge-Coupled Device spectrometer (AvaSpec-2048, 200-1150 nm with resolution $1.4 \mathrm{~nm}$ from Avantes) Apeldoorn, Netherlands. Reflectance data were collected using an aluminum mirror as a reference. The light source employed for reflectance and transmittance measurements was a deuterium-halogen Micropak DH2000BAL (Ocean Insight, Largo, FL, USA), while emission spectra were collected by exciting the sample with a continuous wave laser, Oxxius $405 \mathrm{~nm}$, with power $50 \mathrm{~mW}$. Reflectance and angular resolved transmittance data were modelled by employing a transfer matrix method formalism as described in [33]. The layer thicknesses were employed as fitting parameter for the reflectance data, while the optical functions of PVK, PAA and PS were previously measured and reported in other publications $[43,48]$. The retrieved geometrical thicknesses and the refractive index just mentioned were then employed to model the angular dispersion of the microcavity transmittance spectrum and the local density of photonic states (LPDOS) as described in [49].

Photoluminescence decay was recorded with an angle-resolved setup coupled with a PicoQuant Time-Correlated Single-Photon Counting system (Time Harp 260 PICO board with a temporal resolution of 25 ps, a PMA Hybrid 40 detector, a response time of 250 ps, and a $405 \mathrm{~nm}$ LDH-P-C-405 laser driven (PicoQuant, Berlin, Germany) with a PDL 800B driver with a 5-80 MHz repetition rate as the excitation source) equipped with a Solar Laser Systems monochromator.

\section{Results and Discussion}

Figure 2a reports a schematic and the reflectance spectrum of a microcavity containing the $\mathrm{EuD}_{4}$ TEA:PS composite. The photonic structure consists of two DBRs made of 25 alternating bilayers of PAA and PVK sandwiching a thin film of the emissive composite. The reflectance spectrum is characterized by an intense peak centered at $625 \mathrm{~nm}$ that is assigned to the photonic band gap (PBG) of the microcavity with a reflectance value approaching $100 \%$ and full width half maximum (FWHM) of $70 \mathrm{~nm}$ (marked with \# in Figure 2b). These values agree with previous reports for polymeric microcavities $[33,43]$. The peak is characterized by a minimum positioned at $632 \mathrm{~nm}$, which corresponds to the cavity mode (marked with * in Figure 2b). The spectrum background is instead characterized by a rather complex Fabry-Perot patter, which arises mainly from the constructive and disruptive light interference arising from beams partially reflected from sample external interfaces (marked with ${ }^{\circ}$ in Figure $2 b$ ). The presence of this fringe pattern, together with the large reflectance intensity and spectral width of the PBG, confirm the excellent optical quality of the structure. Indeed, these characteristics would not be detectable in the spectrum in the presence of scattering phenomena in the composite defect layer. The good quality of the microcavity is also testified by the good agreement between the experimental reflectance spectrum and the modelled data, reported as a black dotted line in Figure $2 \mathrm{~b}$ (see experimental section). The calculation allowed us to retrieve geometrical thicknesses of $77 \mathrm{~nm}$ for PVK, $118 \mathrm{~nm}$ for PAA and $266 \mathrm{~nm}$ for the defect layer. Figure 2 also reports the calculated (panel b) and experimental (panel c) angular resolved transmittance spectra for the microcavity as contour plots. In these plots, the incidence angle for light is reported on the y-scale, while the x-scale shows the spectral wavelength. The intensity is instead reported in false colors so that larger transmittances appear in blue and green tones, while lower values appear in red tones. Note that the y-scales for the two plots are reported symmetrically. We note that the two plots are in good agreement. For both, 
at normal incidence $\left(0^{\circ}\right)$ the PBG and the cavity mode (marked respectively with \# and * in Figure $2 \mathrm{~d}$ ) are observed at the same spectral wavelengths detected in the reflectance data of Figure $2 b$. Increasing the collection angle, the spectral position of the two features moves to the short wavelength side of the spectrum, in agreement with the band structure for planar photonic crystals [33].

(a)

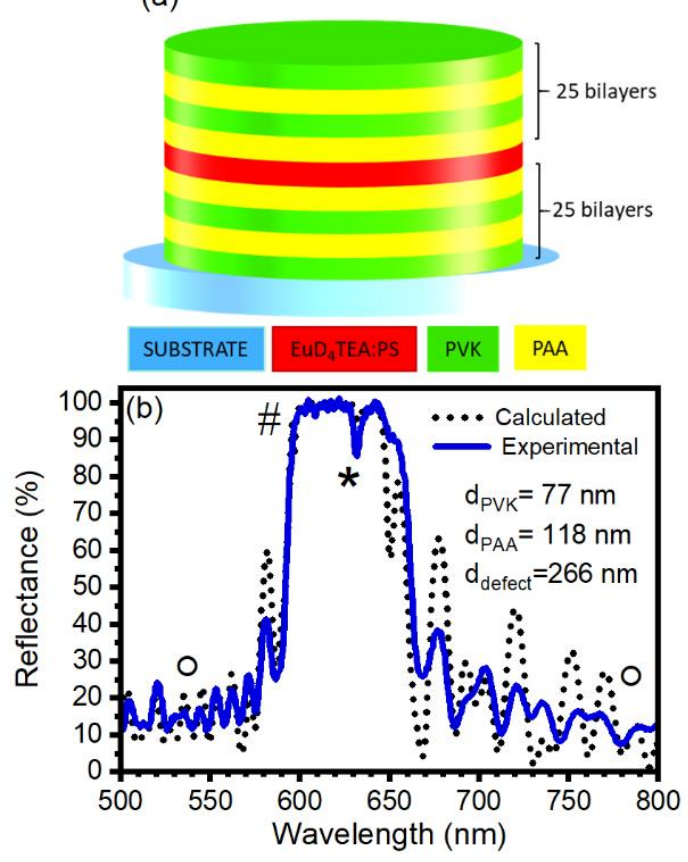

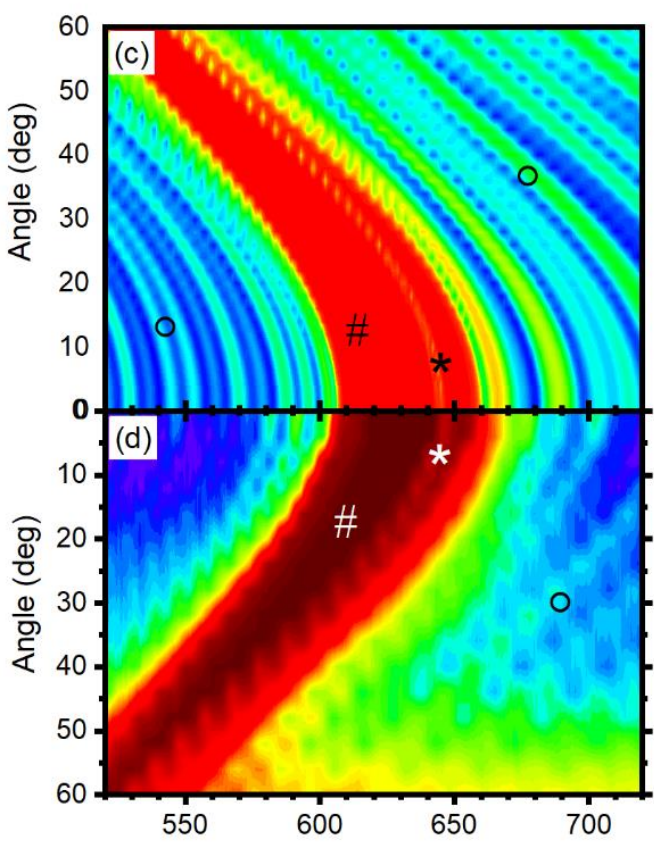

Figure 2. Schematic (a) and reflectance spectrum (b) of a europium tetrakis (dibenzoyl methide) triethylammonium polystyrene (EuD 4 TEA:PS) microcavity made of poly (N-vinylcarbazole) (PVK) and polyacrylic acid (PAA) as dielectric media. Calculated (c) and experimental (d) angular resolved transmittance spectra of the microcavity.

The effect of the photonic crystals on the $\mathrm{EuD}_{4} \mathrm{TEA}$ emission spectrum was investigated trough measurements of steady-state photoluminescence exciting the emitter with a continuous wave laser source at $405 \mathrm{~nm}$. Figure 3 compares the normalized emission of the bare $\mathrm{EuD}_{4} \mathrm{TEA}$ :PS composite casted on a PAA thin film on a glass substrate with the LPDOS and the microcavity emission (see experimental section). As mentioned in the introduction, the emission of the europium complex is sharp and centered in the red part of the visible spectrum. It is characterized by an intense peak at $615 \mathrm{~nm}$ with FWHM of $6 \mathrm{~nm}$ (Figure 3a). Other structures with much lower intensities are also detected at $582 \mathrm{~nm}$, $595 \mathrm{~nm}$ and $703 \mathrm{~nm}$. The calculated LPDOS of the microcavity shows two maxima positioned at $605 \mathrm{~nm}$ and $645 \mathrm{~nm}$, which are assigned to the short wavelength edge of the PBG and to the cavity mode, respectively (Figure 3b). At the PBG frequencies $(610-630 \mathrm{~nm})$, the value of LPDOS is low, but, in agreement with the relatively low dielectric contrast typical of polymer multilayered structures, the density is larger than zero [50-53]. Then, suppression of the europium complex emission intensity is expected in this spectral region. In turn, the emission should be redistributed in the spectral regions where the LPDOS is larger. When observing the emission spectrum of the microcavity collected at normal incidence, it is clear that the photonic environment has a strong effect on the emission linewidth of the $\mathrm{EuD}_{4} \mathrm{TEA}$ (Figure 3c). In agreement with predictions, the main emission peak of the europium complex is suppressed and redistributed at $595 \mathrm{~nm}$ and $645 \mathrm{~nm}$. These wavelengths correspond to the PBG edge and to the cavity mode, respectively (compare with panel b). At this angle, the cavity mode is indeed detuned with respect to the main $\mathrm{EuD}_{4}$ TEA emission (compare with Figure $2 b$ ). 


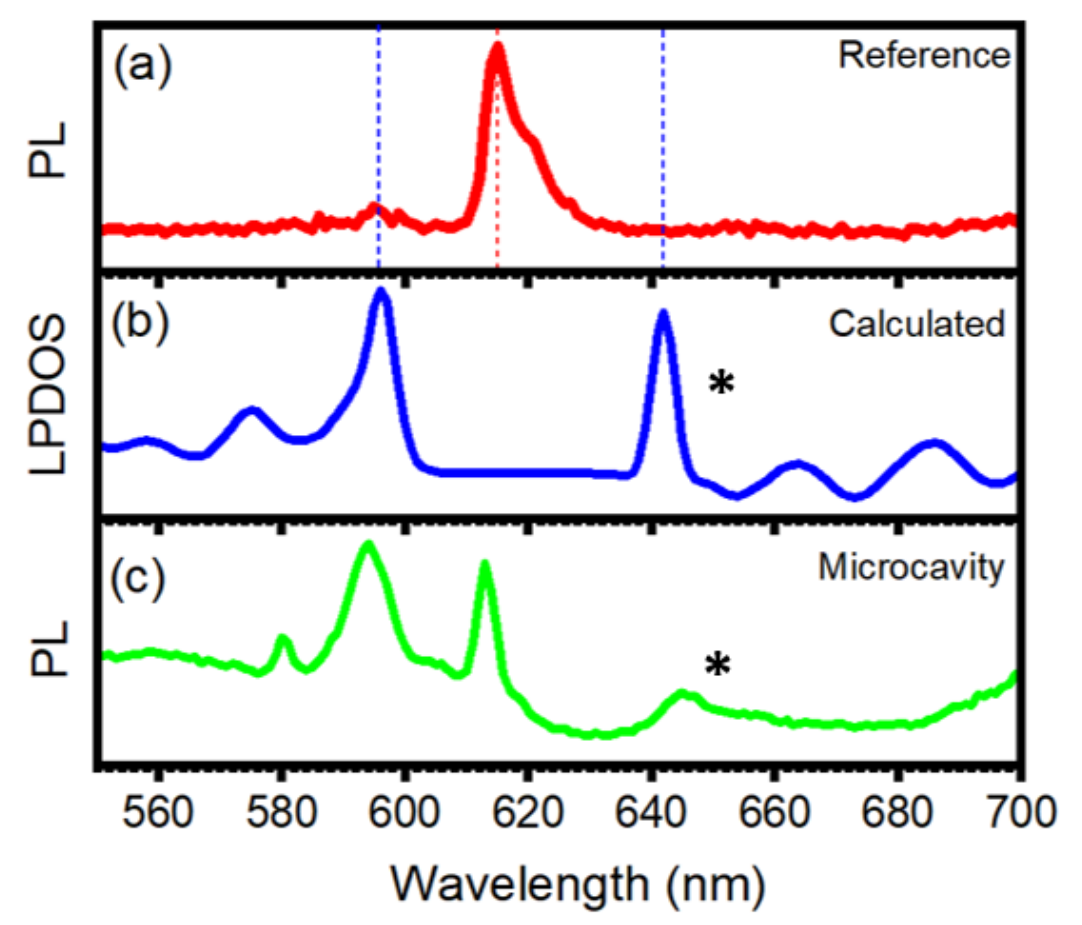

Figure 3. (a) EuD 4 TEA:PS reference emission spectrum, (b) calculated local density of photonic states (LPDOS) for the microcavity and (c) emission spectrum of the microcavity, the microcavity spectral position is marked with $\left(^{*}\right)$.

Figure 4 reports the angular characterization of the sample and compares the reference spectrum with those of the microcavity collected at $0^{\circ}$ (panel a), $28^{\circ}$ (panel b) and $40^{\circ}$ (panel c). The behavior of the sample at normal incidence collection was described in Figure $3 a$ and is reported here for comparison. Because the PBG spectral position is angularly dependent (photon momentum, see Figure 2c,d) at collection angles larger than $0^{\circ}$, the cavity mode is detected at shorter wavelengths with respect to lower collection angles. In agreement, at $28^{\circ}$, the europium emission is spectrally superimposed to the cavity mode (Figure $4 \mathrm{~b}$ ). In this case, the photoluminescence of the microcavity results centered at $613 \mathrm{~nm}$, having a FWHM of $3.7 \mathrm{~nm}$, which correspond to a twofold reduction and to a quality factor $\lambda_{0} / \Delta \lambda=166$, which agrees with previous reports for similar polymer systems [33]. For larger angles, the PBG is again detuned (Figure 4c) and the emission spectra of the reference and of the microcavity are very similar. The overall behavior is reported in Figure $4 \mathrm{~d}$, where the emission spectra of the cavity are stacked. At $0^{\circ}$ (first spectrum from the bottom), we clearly notice three main features positioned at 595,613 and $645 \mathrm{~nm}$ marked in the same order by a red dashed line $\left(595 \mathrm{~nm}\right.$ at $\left.0^{\circ}\right)$, a gray dotted line $\left(613 \mathrm{~nm}\right.$ at $\left.0^{\circ}\right)$ and a black dashed line $\left(645 \mathrm{~nm}\right.$ at $\left.0^{\circ}\right)$. As described above, the features detected at $595 \mathrm{~nm}$ correspond to the short wavelength PBG edge, the one at 613 to the emission peak of the Eu complex, while the one at 645 corresponds to the cavity mode (compare with Figure 3). In agreement with the angular dispersion of the PBG reported in Figure 2c, the spectral position of the peak and of the cavity mode moves toward the shorter wavelengths, and so do the two optical features assigned to the PBG edge and to the cavity mode. Then, increasing the collection angle, the PBG shifts, and suppresses almost entirely the emission of the $\mathrm{EuD}_{4} \mathrm{TEA}$ in the range between $8^{\circ}$ and $24^{\circ}$. At $24^{\circ}$, the cavity mode is spectrally overlapped to the main emission peak. Indeed, the lines tracking the cavity mode and the peak position cross in this region in Figure $4 \mathrm{~d}$. At this point, a sharp peak arises at $613 \mathrm{~nm}$ (black spectrum, $28^{\circ}$ ), and blueshift increases the collection angle up to $32^{\circ}$. At larger angles, the emission peak of the Eu complex results overlap the long wavelength edge of the PBG and it is not affected anymore by the photonic environment. Moreover, starting from $38^{\circ}$, the spectral position of the cavity mode (black dashed line) overlaps the weak emission signal initially positioned 
at $595 \mathrm{~nm}$. These peak results enhance in intensity with respect to a shorter collection angle. Increasing the angle, this signal is angularly redistributed. Indeed, it moves from about $605 \mathrm{~nm}$ in the spectrum collected at $32^{\circ}$ to $581 \mathrm{~nm}$ in the spectrum collected at $44^{\circ}$. Then, at larger angles, the effect of the PBG on the emission fades and the emission profile of the microcavity results is similar to the one of the reference sample (see Figure 4c). To estimate the effect of the microcavity on the overall emission intensity, Figure 4e shows the values of the integrated intensities in the spectral range between $450 \mathrm{~nm}$ and $850 \mathrm{~nm}$ for collection angles ranging from $0^{\circ}$ to $60^{\circ}$. The data show that in the entire angular range, the overall microcavity intensity is one order of magnitude larger than for the reference sample. This data confirms that the microcavity induces an overall intensity enhancement. On the other hand, it is not clear whether this effect arises from the modified LPDOS or from the better light extraction operated by the multilayered structure.
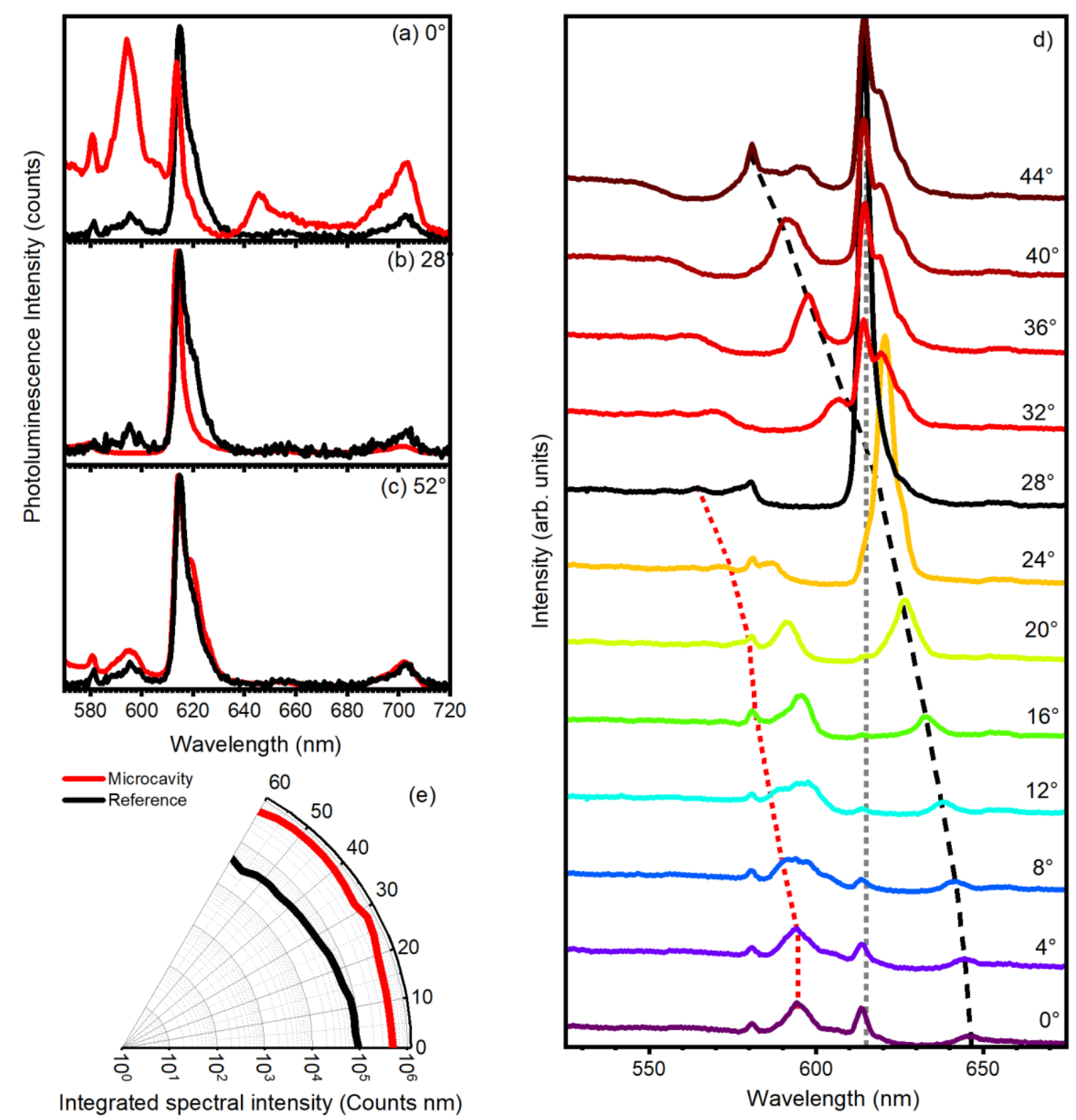

Integrated spectral intensity (Counts $\mathrm{nm}$ )

Figure 4. Normalized steady state emission spectra collected for the $\mathrm{EuD}_{4} \mathrm{TEA}$ microcavity (red line) and for the reference film (black line) collected at $0^{\circ}(\mathbf{a}), 28^{\circ}(\mathrm{b})$ and $52^{\circ}$ (c) with respect the normal incidence direction to the sample plane. (d) angular resolved emission spectra. (e) Angular resolved integrated spectral intensity for the reference and for the microcavity. 
The larger emission intensity from the microcavity suggests that radiative rate enhancement of $\mathrm{EuD}_{4}$ TEA might take place in the photonic structure. To evaluate the effects, we also registered its emission decay at a collection angle of $28^{\circ}$, where the cavity mode superimposes the main fluorescence peak of the complex. Indeed, theory foresees faster decay rates for radiative rate enhancement. Then, when the emission occurs within the cavity mode, where the density of photonic states is larger, the emission should be faster than for the reference, where the density of photonic states in unmodified $[43,52,54,55]$. Figure 5 shows the emission decays for the two samples collected at $615 \mathrm{~nm}$ (compare with Figure 4b). The experimental data (red dots for the microcavity and black dots for the reference sample) were fitted with a biexponential decay. The lifetimes retrieved were $1.2 \mathrm{~ns}$ and $8.9 \mathrm{~nm}$ for the reference sample, while for the microcavity sample we obtained $1.4 \mathrm{~ns}$ and $10.6 \mathrm{~ns}$, respectively. While the difference between the two shorter lifetimes is not significant, as it is within the instrumental resolution, the difference observed for the two longer values is not negligible. The increase in emission lifetime is counterintuitive in a microcavity [43,56-58]. On the other hand, it has been demonstrated that the spontaneous lifetime can be increased by more than a factor of 10 if the emitter is placed in the antinode of the microcavity standing wave or in structures without guided modes $[54,55]$. Then, even though it is not possible to claim radiative rate enhancement without a knowledge of both radiative and non-radiative rates, this is the first report of such a variation in emission lifetime operated by polymer planar photonic crystals.

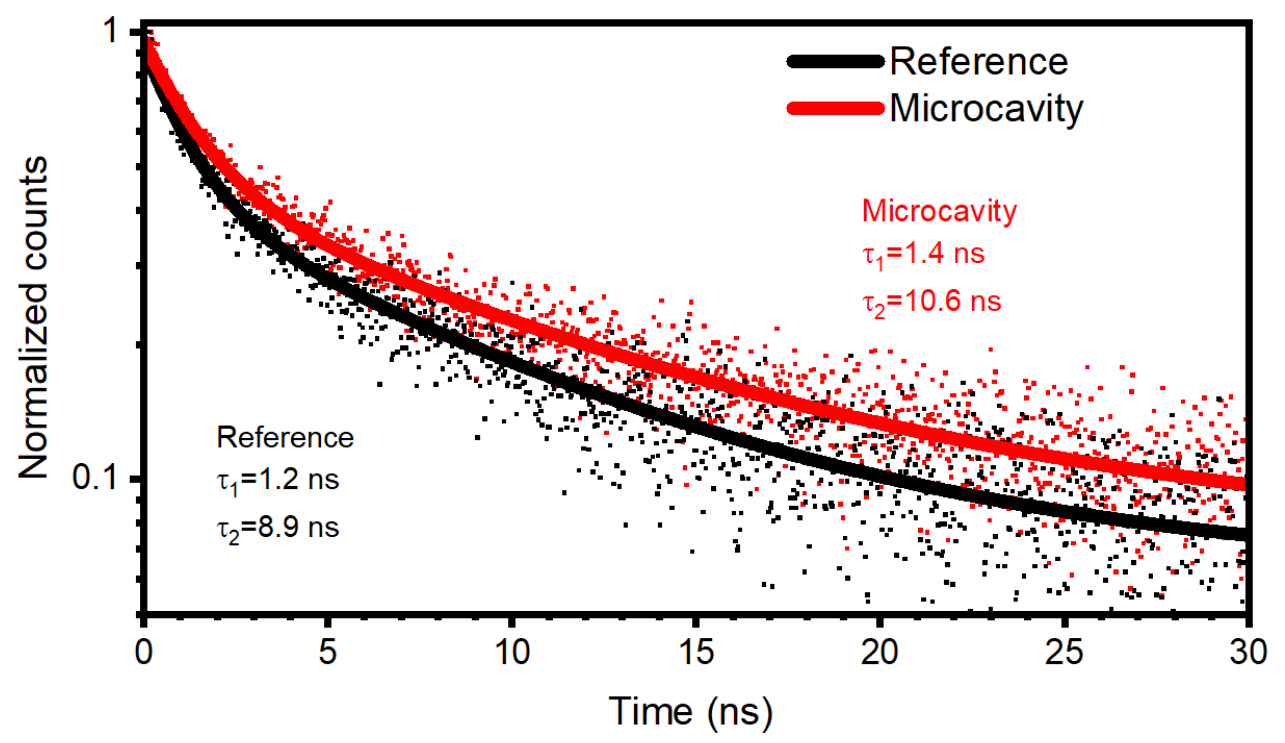

Figure 5. Emission decay collected at $615 \mathrm{~nm}$ for the reference sample (black lines) and for the microcavity (red line). All the data were collected at $28^{\circ}$ from the normal incidence to the sample plane.

\section{Conclusions}

We demonstrated that $\mathrm{EuD}_{4}$ TEA can be efficiently implemented into polystyrene matrices and employed as an emitting medium in polymeric planar microcavities. A characterization of the emission intensity enhancement generated by polymer microcavities demonstrated spectral and directional redistribution of $\mathrm{EuD}_{4} \mathrm{TEA}$ emission assigned to the diverse density of photonic states in the microcavity. The photoluminescence decay of the microcavity suggested that the microcavity plays an active role in the radiative processes occurring in the microcavity. On the other hand, further studies are necessary to investigate possible radiative rate enhancement processes.

Author Contributions: Synthesis, G.T.; diffraction, M.E.-E.; conceptualization, D.C; methodology, P.L.; formal analysis, P.L.; investigation, M.O., A.S.; data curation, P.L.; writing-original draft preparation, P.L.; writing-review and editing, P.L., D.C., M.O., A.S., G.T., M.M.D.; supervision, D.C. All authors have read and agreed to the published version of the manuscript. 
Funding: The work at the University of Genova was funded by PRA 2018 and 2019.

Conflicts of Interest: The authors declare no conflict of interest.

\section{References}

1. Beer, P.D.; Hayes, E.J. Transition Metal and Organometallic Anion Complexation Agents. Coord. Chem. Rev. 2003, 240, 167-189. [CrossRef]

2. Vogler, A.; Kunkely, H. Charge Transfer Excitation of Organometallic Compounds: Spectroscopy and Photochemistry. Coord. Chem. Rev. 2004, 248, 273-278. [CrossRef]

3. İncel, A.; Varlikli, C.; McMillen, C.D.; Demir, M.M. Triboluminescent Electrospun Mats with Blue-Green Emission under Mechanical Force. J. Phys. Chem. C 2017, 121, 11709-11716. [CrossRef]

4. Fontenot, R.S.; Bhat, K.N.; Hollerman, W.A.; Aggarwal, M.D.; Nguyen, K.M. Comparison of the Triboluminescent Yield and Decay Time for Europium Dibenzoylmethide Triethylammonium Synthesized Using Different Solvents. CrystEngComm 2012, 14, 1382. [CrossRef]

5. Hurt, C.R.; McAvoy, N.; Bjorklund, S.; Filipescu, N. High Intensity Triboluminescence in Europium Tetrakis (Dibenzoylmethide)-triethylammonium. Nature 1966, 212, 179. [CrossRef]

6. Xu, H.; Wang, J.; Wei, Y.; Xie, G.; Xue, Q.; Deng, Z.; Huang, W. A Unique White Electroluminescent One-Dimensional Europium(III) Coordination Polymer. J. Mater. Chem. C 2015, 3, 1893-1903. [CrossRef]

7. Jin, X.; Deng, M.; Kaps, S.; Zhu, X.; Hölken, I.; Mess, K.; Adelung, R.; Mishra, Y.K. Study of Tetrapodal ZnO-PDMS Composites: A Comparison of Fillers Shapes in Stiffness and Hydrophobicity Improvements. PLoS ONE 2014, 9, e106991. [CrossRef]

8. Fontenot, R.S.; Hollerman, W.A.; Bhat, K.N.; Aggarwal, M.D. Synthesis and Characterization of Highly Triboluminescent Doped Europium Tetrakis Compounds. J. Lumin. 2012, 132, 1812. [CrossRef]

9. Sweeting, L.M.; Rheingold, A.L. Crystal Disorder and Triboluminescence-Triethylammonium Tetrakis(dibenzoylmethanato)europate. J. Am. Chem. Soc. 1987, 109, 2652. [CrossRef]

10. İncel, A.; Emirdag-Eanes, M.; McMillen, C.D.; Demir, M.M. Integration of Triboluminescent EuD 4 TEA Crystals to Transparent Polymers: Impact Sensor Application. ACS Appl. Mater. Interfaces 2017, 9, 6488-6496. [CrossRef]

11. İncel, A.; Reddy, S.M.; Demir, M.M. A New Method to Extend the Stress Response of Triboluminescent Crystals by Using Hydrogels. Mater. Lett. 2017, 186, 210. [CrossRef]

12. Walton, A.J. Triboluminescence. Adv. Phys. 1977, 26, 887-948. [CrossRef]

13. Hardy, G.E.; Kaska, W.C.; Chandra, B.P.; Zink, J.I. Triboluminescence-Structure Relationships in Polymorphs of Hexaphenylcarbodiphosphorane and Anthranilic Acid, Molecular Crystals, and Salts. JACS 1981, 103, 1074-1079. [CrossRef]

14. Yablonovitch, E. Photonic Crystals: Semiconductors of Light. Sci. Am. 2001, 12, 47. [CrossRef]

15. Sadrai, M.; Hadel, L.; Sauers, R.R.; Husain, S.; Krogh-Jespersen, K.; Westbrook, J.D.; Bird, G.R. Lasing Action in a Family of Perylene Derivatives: Singlet Absorption and Emission Spectra, Triplet Absorption and Oxygen Quenching Constants, and Molecular Mechanics and Semiempirical Molecular Orbital Calculations. J. Phys. Chem. 1992, 96, 7988-7996. [CrossRef]

16. Paternò, G.M.; Iseppon, C.; D’Altri, A.; Fasanotti, C.; Merati, G.; Randi, M.; Desii, A.; Pogna, E.A.A.; Viola, D.; Cerullo, G.; et al. Solution Processable and Optically Switchable 1D Photonic Structures. Sci. Rep. 2018, 8, 3517. [CrossRef]

17. Paternò, G.M.; Moscardi, L.; Donini, S.; Ariodanti, D.; Kriegel, I.; Zani, M.; Parisini, E.; Scotognella, F.; Lanzani, G. Hybrid One-Dimensional Plasmonic-Photonic Crystals for Optical Detection of Bacterial Contaminants. J. Phys. Chem. Lett. 2019, 10, 4980-4986. [CrossRef]

18. Fenzl, C.; Hirsch, T.; Wolfbeis, O.S. Photonic Crystals for Chemical Sensing and Biosensing. Angew. Chem. Int. Ed. 2014, 53, 3318-3335. [CrossRef] [PubMed]

19. von Freymann, G.; Kitaev, V.; Lotsch, B.V.; Ozin, G.A. Bottom-up Assembly of Photonic Crystals. Chem. Soc. Rev. 2013, 42, 2528-2554. [CrossRef]

20. Ye, Z.; Park, J.-M.; Constant, K.; Kim, T.-G.; Ho, K.-M. Photonic Crystal: Energy-Related Applications. J. Photonics Energy 2012, 2, 021012-13. [CrossRef]

21. David, A.; Benisty, H.; Weisbuch, C. Photonic Crystal Light-Emitting Sources. Rep. Prog. Phys. 2012, 75, 126501. [CrossRef] [PubMed] 
22. Ralf, B.W.; Johannes, Ü. 3D Photonic Crystals for Photon Management in Solar Cells. J. Opt. 2012, $14,024003$.

23. Yin, J.; Migas, D.B.; Panahandeh-Fard, M.; Chen, S.; Wang, Z.; Lova, P.; Soci, C. Charge Redistribution at GaAs/P3HT Heterointerfaces with Different Surface Polarity. J. Phys. Chem. Lett. 2013, 4, 3303-3309. [CrossRef]

24. Sprengard, R.; Bonrad, K.; Daeubler, T.K.; Frank, T.; Hagemann, V.; Köhler, I.; Pommerehne, J.; Ottermann, C.R.; Voges, F.; Vingerling, B. OLED Devices for Signage Applications: A Review of Recent Advances and Remaining Challenges. In Organic Light-Emitting Materials and Devices VIII; SPIE: Bellingham, WA, USA, 2004. Available online: https://www.spiedigitallibrary.org/conference-proceedings-of-spie/5519/0000/ OLED-devices-for-signage-applications--a-review-of-recent/10.1117/12.567131.short?SSO=1 (accessed on 9 April 2020).

25. Shah, A.; Torres, P.; Tscharner, R.; Wyrsch, N.; Keppner, H. Photovoltaic Technology: The Case for Thin-Film Solar Cells. Science 1999, 285, 692-698. [CrossRef]

26. Appold, M.; Gallei, M. Bio-Inspired Structural Colors Based on Linear Ultrahigh Molecular Weight Block Copolymers. ACS Appl. Polym. Mater. 2019, 1, 239-250. [CrossRef]

27. Kang, H.S.; Lee, J.; Cho, S.M.; Park, T.H.; Kim, M.J.; Park, C.; Lee, S.W.; Kim, K.L.; Ryu, D.Y.; Huh, J.; et al. Printable and Rewritable Full Block Copolymer Structural Color. Adv. Mater. 2017, 29, 1700084. [CrossRef]

28. Nucara, L.; Piazza, V.; Greco, F.; Robbiano, V.; Cappello, V.; Gemmi, M.; Cacialli, F.; Mattoli, V. Ionic Strength Responsive Sulfonated Polystyrene Opals. ACS Appl. Mater. Interfaces 2017, 9, 4818-4827. [CrossRef]

29. Mele, E.; Di Benedetto, F.; Persano, L.; Cingolani, R.; Pisignano, D. Multilevel, Room-Temperature Nanoimprint Lithography for Conjugated Polymer-Based Photonics. Nano Lett. 2005, 5, 1915-1919. [CrossRef]

30. Giusto, P.; Lova, P.; Manfredi, G.; Gazzo, S.; Srinivasan, B.; Radice, S.V.; Comoretto, D. Colorimetric Detection of Perfluorinated Compounds by All-Polymer Photonic Transducers. ACS Omega 2018, 3, 7517-7522. [CrossRef]

31. Lova, P. Selective Polymer Distributed Bragg Reflector Vapor Sensors. Polymers 2018, 10, 1161. [CrossRef]

32. Lova, P.; Manfredi, G.; Bastianini, C.; Mennucci, C.; Buatier de Mongeot, F.; Servida, A.; Comoretto, D. Flory-Huggins Photonic Sensors for the Optical Assessment of Molecular Diffusion Coefficients in Polymers. ACS Appl. Mater. Interfaces 2019, 11, 16872-16880. [CrossRef] [PubMed]

33. Lova, P.; Manfredi, G.; Comoretto, D. Advances in Functional Solution Processed Planar One-Dimensional Photonic Crystals. Adv. Opt. Mater. 2018, 6, 1800730. [CrossRef]

34. Song, H.; Singer, K.; Wu, Y.; Zhou, J.; Lott, J.; Andrews, J.; Hiltner, A.; Baer, E.; Weder, C.; Bunch, R.; et al. Layered Polymeric Optical Systems Using Continuous Coextrusion. Proc. SPIE 2009, 7467, 74670A.

35. Singer, K.D.; Kazmierczak, T.; Lott, J.; Song, H.; Wu, Y.; Andrews, J.; Baer, E.; Hiltner, A.; Weder, C. Melt-processed All-polymer Distributed Bragg Reflector Laser. Opt. Express 2008, 16, 10358-10363. [CrossRef] [PubMed]

36. Palatnik, A.; Tischler, Y.R. Solid-state Rhodamine 6G Microcavity Laser. IEEE Photonics Technol. Lett. 2016, 28, 1823-1826. [CrossRef]

37. Lee, T.-W.; Park, O.O.; Cho, H.N.; Kim, D.Y.; Kim, Y.C. Low-threshold Lasing in A Microcavity of Fluorene-Based Liquid-Crystalline Polymer Blends. J. Appl. Phys. 2003, 93, 1370. [CrossRef]

38. Tessler, N.; Denton, G.J.; Friend, R.H. Lasing from Conjugated-Polymer Microcavities. Nature 1996, 382, 695-697. [CrossRef]

39. Manfredi, G.; Lova, P.; Di Stasio, F.; Rastogi, P.; Krahne, R.; Comoretto, D. Lasing From Dot-in-Rod Nanocrystals in Planar Polymer Microcavities. RSC Adv. 2018, 8, 13026-13033. [CrossRef]

40. Galfsky, T.; Sun, Z.; Considine, C.R.; Chou, C.-T.; Ko, W.-C.; Lee, Y.-H.; Narimanov, E.E.; Menon, V.M. Broadband Enhancement of Spontaneous Emission in Two-Dimensional Semiconductors Using Photonic Hypercrystals. Nano Lett. 2016, 16, 4940-4945. [CrossRef]

41. Valappil, N.V.; Luberto, M.; Menon, V.M.; Zeylikovich, I.; Gayen, T.K.; Franco, J.; Das, B.B.; Alfano, R.R. Solution Processed Microcavity Structures with Embedded Quantum Dots. Photonics Nanostruct. Fundam. Appl. 2007, 5, 184-188. [CrossRef]

42. Menon, V.M.; Luberto, M.; Valappil, N.V.; Chatterjee, S. Lasing from InGaP Quantum Dots in a Spin-Coated Flexible Microcavity. Opt. Express 2008, 16, 19535-19540. [CrossRef] [PubMed]

43. Lova, P.; Grande, V.; Manfredi, G.; Patrin, M.; Herbst, S.; Würthner, F.; Comoretto, D. All-Polymer Photonic Microcavities Doped with Perylene Bisimide J-Aggregates. Adv. Opt. Mater. 2017, 5, 1700523. [CrossRef] 
44. Lova, P.; Giusto, P.; Stasio, F.D.; Manfredi, G.; Paternò, G.M.; Cortecchia, D.; Soci, C.; Comoretto, D. All-Polymer Methylammonium Lead Iodide Perovskite Microcavity. Nanoscale 2019, 11, 8978-8983. [CrossRef] [PubMed]

45. Lova, P.; Cortecchia, D.; Soci, C.; Comoretto, D. Solution Processed Polymer-ABX 4 Perovskite-Like Microcavities. Appl. Sci. 2019, 9, 5203. [CrossRef]

46. Comoretto, D.; Cuniberti, C.; Musso, G.F.; Dellepiane, G.; Speroni, F.; Botta, C.; Luzzati, S. Optical Properties and Long-Lived Charged Photoexcitations in Polydiacetylenes. Phys. Rev. B 1994, 49, 8059-8066. [CrossRef] [PubMed]

47. Moroni, L.; Salvi, P.R.; Gellini, C.; Dellepiane, G.; Comoretto, D.; Cuniberti, C. Two-photon Spectroscopy of Pi-Conjugated Polymers: The Case of Poly 1,6-Bis(3,6-Dihexadecyl-N-Carbazolyl)-2,4-Hexadiyne (Polydchd-Hs). J. Phys. Chem A 2001, 105, 7759-7764. [CrossRef]

48. Frezza, L.; Patrini, M.; Liscidini, M.; Comoretto, D. Directional Enhancement of Spontaneous Emission in Polymer Flexible Microcavities. J. Phys. Chem. C 2011, 115, 19939-19946. [CrossRef]

49. Rybin, M.V.; Zherzdev, A.V.; Feoktistov, N.A.; Pevtsov, A.B. Effect of photonic crystal stop-band on photoluminescence of a $-\mathrm{Si}_{1-\mathrm{x}} \mathrm{C}_{\mathrm{x}}$ : H. Phys. Rev. B 2017, 95, 165118. [CrossRef]

50. Berti, L.; Cucini, M.; Di Stasio, F.; Comoretto, D.; Galli, M.; Marabelli, F.; Manfredi, N.; Marinzi, C.; Abbotto, A. Spectroscopic Investigation of Artificial Opals Infiltrated with a Heteroaromatic Quadrupolar Dye. J. Phys. Chem. C 2010, 114, 2403-2413. [CrossRef]

51. Morandi, V.; Marabelli, F.; Amendola, V.; Meneghetti, M.; Comoretto, D. Light Localization Effect on the Optical Properties of Opals Doped with Gold Nanoparticles. J. Phys. Chem. C 2008, 112, 6293-6298. [CrossRef]

52. Barth, M.; Gruber, A.; Cichos, F. Spectral and Angular Redistribution of Photoluminescence near a Photonic Stop Band. Phys. Rev. B 2005, 72, 085129. [CrossRef]

53. Hagler, T.W.; Pakbaz, K.; Voss, K.F.; Heeger, A.J. Enhanced Order and Electronic Delocalization in Conjugated Polymers Oriented by Gel Processing in Polyethylene. Phys. Rev. B 1991, 44, 8652-8666. [CrossRef] [PubMed]

54. Björk, G.; Machida, S.; Yamamoto, Y.; Igeta, K. Modification of Spontaneous Emission Rate in Planar Dielectric Microcavity Structures. Phys. Rev. A 1991, 44, 669-681. [CrossRef]

55. Björk, G. On the Spontaneous Lifetime Change in an Ideal Planar Microcavity-Transition from a Mode Continuuum to Quantized Modes. IEEE J. Quantum Electron. 1994, 30, 2314-2318. [CrossRef]

56. Vos, W.L.; Sprik, R.; van Blaaderen, A.; Imhof, A.; Lagendijk, A.; Wegdam, G.H. Strong Effects of Photonic Band Structures on the Diffraction of Colloidal Crystals. Phys. Rev. B 1996, 53, 16231. [CrossRef] [PubMed]

57. Baba, T.; Sano, D. Low-Threshold Lasing and Purcell Effect in Microdisk Lasers at Room Temperature. IEEE J. Sel. Top. Quantum Electron. 2003, 9, 1340-1346. [CrossRef]

58. Gerard, J.M.; Gayral, B. Strong Purcell Effect for Inas Quantum Boxes in Three-Dimensional Solid-State Microcavities. J. Light. Technol. 1999, 17, 2089-2095. [CrossRef] 